\title{
Erratum: Phytochemical composition and antioxidant and antimicrobial activities of Pergularia daemia
}

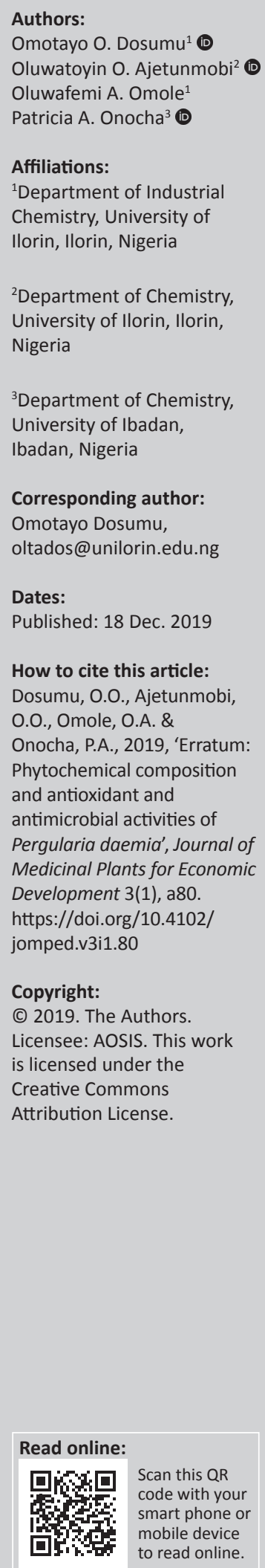

In the original article published the second author's last name was spelled incorrectly as Ajetumobi. This has been corrected to Ajetunmobi in the 'Authors' and the 'How to cite this article' sections.

The last author's affiliation was incorrectly indicated as 'University of Ilorin'. This has been corrected in the 'Affiliations' section of the article to the 'University of Ibadan, Ibadan, Nigeria'.

The publisher apologises for any inconvenience caused. 


\section{Phytochemical composition and antioxidant and antimicrobial activities of Pergularia daemia}

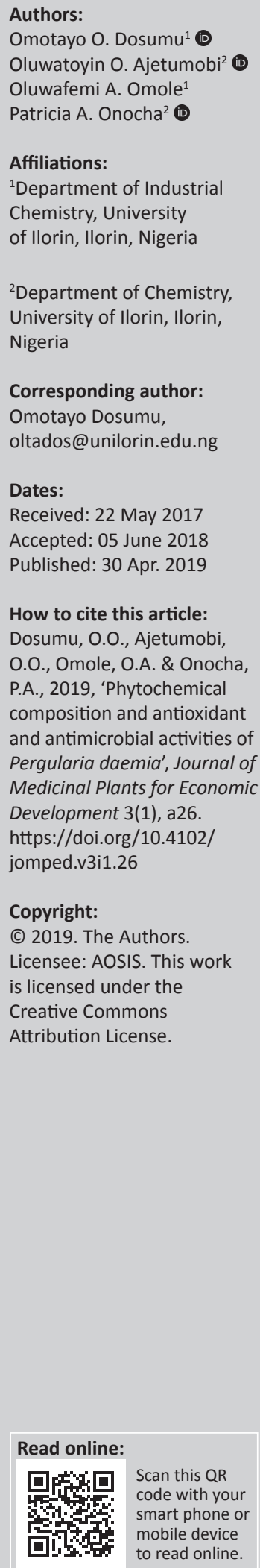

Background: Pergularia daemia of the Asteraceae family has wide use in ethno-medicine. It is established to have pharmacologicall activity with potential medicinal significance as an antifungal, antioxidant, antimicrobial, antiinflamatory, analgesic, fertility, hepatoprotective and antic ancer agent.

Aim: This study estimated the qualitative and quantitative amount of of phytochemicals in Pergularia daemia plant and the and antioxidant capacity was also determined.

Setting: The fresh plants of P. Daemia were collected from Ido-Ekiti, Ekiti State, Nigeria and was identified at Plant Biology Department of the University of Ilorin, Nigeria. The samples were air-dried, pulverized and stored properly for investigation.

Method: Both qualitative and quantitative phytochemical analyses of the leaves and stem were determined through n-hexane, ethyl acetate and ethanol extracts of $P$. daemia. Antioxidant activities of the extracts were evaluated with 2,2-diphenyl-1-picryhydroxyl (DPPH). The antibacterial and antifungal assay of the extracts were determing by dissolving $1 \mathrm{mg}$ of the extract in $5 \mathrm{~mL}$ of the extracting solvent to give a $200 \mu \mathrm{g} / \mathrm{mL}$ solution.

Results: Flavonoids, steroids, terpenoids and glycosides were present in all the stem and leaf extracts of $P$. daemia. The total phenolic content of the extracts ranged from $15.898 \pm 0.111$ $\mathrm{mgGA} / \mathrm{g}$ to $54.679 \pm 0.675 \mathrm{mgGA} / \mathrm{g}$. The leaf has higher concentration of flavonoids than the stem and the ethanol extracts contain highest content of flavonoids. The concentration of the ethanol extract of the leaf was $400.196 \mathrm{mg} \mathrm{QE} / \mathrm{g}$ while that of ethyl acetate and n-hexane were $388.627 \mathrm{mg} \mathrm{QE} / \mathrm{g}$ and $338.725 \mathrm{mg} \mathrm{QE} / \mathrm{g}$ respectively at $10 \mathrm{mg} / \mathrm{mL}$. Ethanol extracts has the highest concentration of phenolic compounds, flavonoids and antioxidant capacity.

Conclusion: The results derived from this study validate the ethno-medicinal use of the aerial parts of P. daemia.

Keywords: Pergularia daemia; Phytochemical; Flavonoid concentration; Phenolic content; Antioxidant activity; Antimicrobial.

\section{Introduction}

The oldest form of treatment known to humans is the application of herbs to cure ailments and diseases. The prehistoric medical systems such as Ayurveda, Siddha and Homoeopathy use herbal formulations to treat various ailments (Kelly 2009). According to the World Health Organization (WHO), more than $80 \%$ of the global population in poor and underdeveloped countries rely primarily on traditional plant-based medicines for their primary health care needs because pharmaceuticals are not available or are relatively expensive (WHO 2002). Even in developed countries where pharmaceuticals are readily accessible, many still prefer herbal drugs over the pharmaceutical drugs (Sridevi, Prema \& Sekar 2014).

This development has attracted the interest of pharmaceutical companies and has led to serious research in the field of medicinal plants (Kotnis et al. 2004). In this study, the medicinal plant of interest is Pergularia daemia, which belongs to the Asteraceae family. It is a slender, hispid, fetidsmelling perennial climber with small, white flowers and is commonly found in central India and Africa. It is used in ethno-medicine and has been proved to be pharmacologically active with potential medicinal significance as an antifungal, antioxidant, antimicrobial, anti-inflammatory, analgesic, antipyretic, fertility, hepatoprotective and anticancer agent (Karthishwaran \& Mirunalini 2010). The plant contains phytochemicals such as alkaloids, glycosides, flavonoids, terpenoids, phenols, steroids and saponins (Sridevi et al. 2014). There is a dearth of scientifically documented literature on the medicinal benefits of this abundant plant; hence, this study was undertaken to estimate the total phenolic and flavonoid concentrations of n-hexane, ethyl acetate and ethanol extracts from the stem and leaves of $P$. daemia. The qualitative phytochemical constituents and antimicrobial activities were also evaluated. 


\section{Materials and methods}

\section{Plant collection}

The fresh plants of $P$. daemia were collected on 02 November 2014 from Ido-Ekiti in Ekiti State, Nigeria. The plant samples were authenticated at the Department of Plant Biology herbarium, University of Ilorin, Nigeria, and a specimen copy with number UIH002/1136 was deposited.

\section{Extract preparation}

Stems and leaves of the plant were air-dried separately at room temperature $\left(25^{\circ} \mathrm{C}\right)$ and were pulverised after drying. Of the pulverised sample, $400 \mathrm{~g}$ was kept in contact with $1 \mathrm{~L}$ n-hexane in a stoppered glass container for 5 days with frequent agitation (Ncube, Afolayan \& Okoh 2008). The extract was decanted and filtered through a cotton plug funnel and Whatman no.1 filter paper. The filtrate from the n-hexane extraction was concentrated under vacuum using rotary evaporator. Subsequent extraction using the above procedure was also carried out to obtain crude ethyl acetate and ethanol extracts independently.

\section{Phytochemical screening}

\section{Qualitative analysis of phytochemicals}

Constituents of the $P$. daemia extracts were screened using standard procedures to identify the metabolites present (Harborne 1973; Okwu 2001; Rahilla et al. 1994; Sofowora 1993). The major metabolites analysed for were alkaloids, tannins, anthraquinones, saponins, flavonoids, terpenoids, glycosides, steroids and phenols.

\section{Quantitative analysis of phytochemicals}

Total phenolic content: The total phenolic content in the plant extracts was determined using the spectrophotometric method (Singleton, Orthofer \& Lamuela-Raventos 1999). Concentrations of $1 \mathrm{mg} / \mathrm{mL}, 5 \mathrm{mg} / \mathrm{mL}$ and $10 \mathrm{mg} / \mathrm{mL}$ of methanolic solution of the extract were prepared and used in the analysis. The reaction mixture was prepared by adding

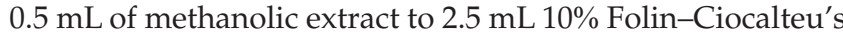
reagent and $2.5 \mathrm{~mL} 7.5 \% \mathrm{NaHCO}_{3}$. Blank was concomitantly prepared, containing $0.5 \mathrm{~mL}$ methanol, $2.5 \mathrm{~mL} \mathrm{10 \%} \mathrm{Folin-}$ Ciocalteu's reagent and $2.5 \mathrm{~mL} 7.5 \%$ of $\mathrm{NaHCO}_{3}$. The mixture was thereafter incubated in a $45^{\circ} \mathrm{C}$ thermo-stated water bath in a dark cupboard for $45 \mathrm{~min}$. The absorbance was then determined at a wavelength of $765 \mathrm{~nm}$ using a spectrophotometer (Deckmann GU750). The mixture was prepared in triplicate for each analysis and the mean value of absorbance was obtained. A solution of gallic acid, which serves as a standard, was prepared in methanol to achieve the concentration of $0.5 \mathrm{mg} / \mathrm{mL}$. This solution was then diluted to obtain concentrations of $25 \mu \mathrm{g} / \mathrm{mL}, 12.5 \mu \mathrm{g} / \mathrm{mL}$, $6.25 \mu \mathrm{g} / \mathrm{mL}, 3.13 \mu \mathrm{g} / \mathrm{mL}, 1.56 \mu \mathrm{g} / \mathrm{mL}$ and $0.78 \mu \mathrm{g} / \mathrm{mL}$, and the calibration line was constructed. Based on the measurement of the absorbance, the concentration of phenolics was determined $(\mu \mathrm{g} / \mathrm{mL})$ from the calibration line and the total phenolic content in the extracts was expressed in terms of gallic acid equivalent (mg of GA/g of extract).
Determination of flavonoid content: The total flavonoids in the plant extracts were determined using the spectrophotometric method (Quettier et al. 2000). Methanol was used to prepare the extracts with concentrations of $1 \mathrm{mg} / \mathrm{mL}, 5 \mathrm{mg} / \mathrm{mL}$ and $10 \mathrm{mg} / \mathrm{mL}$, which were used in the analysis. Of each solution of the extracts, $1 \mathrm{~mL}$ was added to $1 \mathrm{~mL}$ of $2 \% \mathrm{AlCl}_{3}$ solution, which was also prepared in methanol. The samples were incubated for an hour at room temperature and the absorbance was then read using a spectrophotometer at a wavelength of $415 \mathrm{~nm}$ (Deckmann GU750). The samples were prepared in triplicate for each analysis and the mean value of absorbance was obtained. The quercetin equivalent and calibration curve were evaluated by preparing quercetin solutions at concentrations varying from $10 \mu \mathrm{g} / \mathrm{mL}$ to $100 \mu \mathrm{g} / \mathrm{mL}$ in methanol. Based on the measured absorbance, the concentration of flavonoids was determined $(\mu \mathrm{g} / \mathrm{mL})$ on the calibration line and the flavonoid contents in the extracts were expressed in terms of quercetin equivalent ( $\mathrm{mg}$ of $\mathrm{QE} / \mathrm{g}$ of extract).

\section{Antioxidant activity}

\section{2,2-diphenyl-1-picrylhydrazyl free radical scavenging}

The ability of the plant extracts to scavenge DPPH (2,2-diphenyl-1-picrylhydrazyl) free radicals was assessed following the method of Chang et al. (2001) and Kumarasamy et al. (2007). The stock solution of the extracts was prepared in methanol to achieve the concentration of $1 \mathrm{mg} / \mathrm{mL}$. Dilutions were made to obtain concentrations of $500 \mu \mathrm{g} / \mathrm{mL}$, $250 \mu \mathrm{g} / \mathrm{mL}, 125 \mu \mathrm{g} / \mathrm{mL}, 62.5 \mu \mathrm{g} / \mathrm{mL}, 31.25 \mu \mathrm{g} / \mathrm{mL}$, $15.62 \mu \mathrm{g} / \mathrm{mL}, 7.81 \mu \mathrm{g} / \mathrm{mL}, 3.90 \mu \mathrm{g} / \mathrm{mL}, 1.99 \mu \mathrm{g} / \mathrm{mL}$ and 0.97 $\mu \mathrm{g} / \mathrm{mL}$. The prepared solution $(1 \mathrm{~mL})$ was mixed with $1 \mathrm{~mL}$ of methanolic solution of DPPH of concentration $1 \mathrm{mg} / \mathrm{mL}$. After 30 min of incubation in the dark at room temperature, the absorbance was recorded at $517 \mathrm{~nm}$ with a spectrophotometer. A control sample containing $1 \mathrm{~mL}$ of methanol and $1 \mathrm{~mL}$ of methanolic DPPH solution was set alongside. Percentage inhibition was calculated using the equation below, while $\mathrm{IC}_{50}$ (inhibitory concentration at 50\%) was estimated from the percentage inhibition versus log concentration plot, using a non-linear regression algorithm:

$\%$ inhibition $=($ A of control - A of sample $/$ A of control) $\times 100$

[Eqn 1]

\section{Antimicrobial assay: Antibacterial and antifungal activities}

Cultures of six human pathogenic bacteria made up of four gram-negative and two gram-positive species were used for the antibacterial assay. Salmonella typhi (UCH 4801), Escherichia coli (UCH 0026), Pseudomonas aeruginosa (UCH 1102 ) and Klebsiella pneumoniae (UCH 2894) were the gramnegative species that were used and Bacillus subtilis (UCH 7423) and Staphylococcus aureus (UCH 2473) were the gram-positive species. All the microorganisms used were clinical strains from the Medical Microbiology Laboratory of the University College Hospital, University of Ibadan, Ibadan, Nigeria. For the antifungal assay, four fungi, including Candida albicans, Aspergillus niger, Rhizopus stolonifier and Penicillium notatum, were used. 
The sample extracts that were used for the antimicrobial sensitivity test were prepared by dissolving $1 \mathrm{mg}$ of the extract in $5 \mathrm{~mL}$ of the extracting solvents, that is, n-hexane, ethyl acetate and ethanol, to make a $200-\mu \mathrm{g} / \mathrm{mL}$ solution. By serial dilution, subsequent concentrations of $100 \mu \mathrm{g} / \mathrm{mL}$, $50 \mu \mathrm{g} / \mathrm{mL}, 25 \mu \mathrm{g} / \mathrm{mL}, 12.5 \mu \mathrm{g} / \mathrm{mL}$ and $6.25 \mu \mathrm{g} / \mathrm{mL}$ were prepared. Gentamycin $(5 \mu \mathrm{g} / \mathrm{mL})$ and tioconazole $(0.7 \mu \mathrm{g} / \mathrm{mL})$ were used as reference antibacterial and antifungal compounds, respectively.

In the antibacterial assay, an overnight culture of the organism was prepared by taking a loop full of the organism from stock and inoculating into a sterile nutrient broth of $5 \mathrm{~mL}$ and then incubated for $24 \mathrm{~h}$ at $37^{\circ} \mathrm{C}$. From the overnight culture, $0.1 \mathrm{~mL}$ of the organism was taken and put into $9.9 \mathrm{~mL}$ of sterile distilled water to get 1:100 $\left(10^{-2}\right)$ dilution of the organism. From the diluted organism $\left(10^{-2}\right), 0.2 \mathrm{~mL}$ was taken into the prepared sterile nutrient agar, which was maintained at $45^{\circ} \mathrm{C}$, and aseptically poured into sterile petri dishes and allowed to solidify for $60 \mathrm{~min}$. Using a sterile cork borer of $8 \mathrm{~mm}$ diameter, wells were made according to the number of graded concentrations. In each well, the different graded extract concentrations were poured, and this was performed in duplicates. The plates were allowed to stay on the bench for $2 \mathrm{~h}$ to allow for pre-diffusion. The plates were then incubated upright in the incubator for $24 \mathrm{~h}$ at $37^{\circ} \mathrm{C}$ (Oloyede et al. 2010; Onocha \& Ali 2010).

In the fungal activity inhibition study, surface plate method was used. Sterile sabouraud dextrose agar $(62 \mathrm{~g} / \mathrm{L})$ was prepared accordingly and aseptically poured into the sterile plates in duplicates and allowed to solidify properly. A volume of $0.2 \mathrm{~mL}$ of the organism was spread on the surface of the agar using a petri dish to cover the entire surface of the agar. Then, eight wells were bored using a sterile cork borer of $8 \mathrm{~mm}$ diameter. The graded concentrations of the extract were put into the wells accordingly, including the controls. All the plates were left on the bench for $2 \mathrm{~h}$ to allow the extract to diffuse properly into the agar, that is, pre-diffusion. The plates were incubated at $25^{\circ} \mathrm{C}$ for $72 \mathrm{~h}$. Solvents of extraction were used as control, while gentamycin $(5 \mu \mathrm{g} / \mathrm{mL})$ and tioconazole $(0.7 \mu \mathrm{g} / \mathrm{mL})$ were used as standard reference drugs in the study (Bayer et al. 1986).

\section{Statistical analysis}

All experimental measurements were carried out in triplicate and are expressed as an average of three analyses \pm standard error. SPSS (Chicago, IL) statistical software package (SPSS for Windows, ver. II, 2004) was used to determine the magnitude of correlation between the variables.

\section{Results and discussion Phytochemical screening of the crude extract}

The phytochemical screening results (Table 1) showed the presence of a high content of glycosides, steroids, terpenoids and flavonoids in all the extracts of both the stem and leaf of P. daemia.

Tannins and saponins were observed in the ethanol extracts of the stem and leaf. Anthraquinones were detected in small quantities in n-hexane extracts of both the stem and the leaf. The presence of flavonoids, steroids, terpenoids and glycosides was high in all the extracts. Tannins, alkaloids, saponins and phenols are present in polar solvents extracts, that is, ethyl acetate and ethanol extracts. It is worth mentioning that the high concentration of all the metabolites in the ethanol extract, except for anthraquinone, confirms ethanol as the better extracting solvent of the three solvents. Ethanol, being a polar solvent and close in polarity to water, lends credence to the efficiency of the aqueous extracts of this plant as used in folk medicine. The phytochemicals are responsible for the therapeutic efficiencies and efficacies of medicinal plants (Shoge, Ndukwe \& Amupitan 2011) and are present in high concentrations in ethanol, a polar solvent. The presence of this phytochemical in the extracts of the plant may therefore be responsible for the detoxifying action and antimicrobial, antioxidant and anti-inflammatory activities of the plant (Li et al. 2004; Yen, Duh \& Chuang 2000). It is therefore not surprising that $P$. daemia has found extensive application as an antioxidant, an analgesic, a hepatoprotective substance and as an anticancer herb in traditional medicine (Karthishwaran \& Mirunalini 2010). The presence of some of the above-mentioned metabolites in $P$. daemia had earlier been detected by Sridevi et al. (2014) in a similar study.

\section{Total phenolic content of the plant extracts}

The total phenolic content of the $P$. daemia extracts using Folin-Ciocalteu's reagent is expressed in terms of gallic acid equivalent (the standard curve equation: $y=0.0052 x$, $\left.R^{2}=0.9905\right)$. The total phenolic content in the examined extracts ranged from $15.898 \pm 0.111 \mathrm{mg} \mathrm{GA} / \mathrm{g}$ to $54.679 \pm$ $0.675 \mathrm{mg} \mathrm{GA} / \mathrm{g}$. Ethanol extracts from the stem recorded

TABLE 1: Phytochemical composition of Pergularia daemia stem and leaf.

\begin{tabular}{|c|c|c|c|c|c|c|}
\hline \multirow{2}{*}{$\begin{array}{l}\text { Phytochemical } \\
\text { constituents }\end{array}$} & \multicolumn{3}{|c|}{ Stem extracts } & \multicolumn{3}{|c|}{ Leaf extracts } \\
\hline & n-Hexane & Ethyl acetate & Ethanol & n-Hexane & Ethyl acetate & Ethanol \\
\hline Alkaloids & - & - & ++ & - & ++ & +++ \\
\hline Saponins & - & - & ++ & - & - & ++ \\
\hline Flavonoids & +++ & +++ & +++ & +++ & +++ & +++ \\
\hline Steroids & +++ & +++ & +++ & +++ & +++ & +++ \\
\hline Terpenoids & +++ & +++ & +++ & +++ & +++ & +++ \\
\hline Glycosides & ++ & +++ & +++ & ++ & +++ & +++ \\
\hline Tannins & - & - & ++ & - & - & +++ \\
\hline Phenols & - & ++ & +++ & - & +++ & +++ \\
\hline Anthraquinones & + & - & - & + & - & - \\
\hline
\end{tabular}

+++, high concentration; ++, medium concentration; +, low concentration; -, absent. 
the presence of high concentrations of phenolic compounds, while ethyl acetate and n-hexane extracts recorded medium concentration. The polarity of solvents is directly related to extraction efficiency; therefore, polar solvents give better extraction than non-polar solvents (Mohsen \& Ammar 2008; Zhou \& Yu 2004). Ethanol affords 54.679\% and 34.167\% GA/g for leaf and stem extracts, respectively, while $18.654 \%$ and $15.888 \%$ were recorded for n-hexane extracts of leaf and stem, respectively. The total phenolic content of $1 \mathrm{mg} / \mathrm{mL}, 5 \mathrm{mg} / \mathrm{mL}$ and $10 \mathrm{mg} / \mathrm{mL}$ of each extract was determined in triplicate.

Phenolic compounds play a key role as antioxidants or free radical scavengers. The antioxidant activity of the phenolic compounds is mainly because of their redox properties, which absorb and neutralise free radicals, triplet oxygen or decomposing peroxides (Osawa 1994). It has also been noted that phenolic compounds provide antimutagenic and anticarcinogenic actions in humans when approximately $1.0 \mathrm{~g}$ of mixed antioxidant compounds were consumed daily from vegetable and fruit diet over a short period of time (Tanaka et al. 1998).

The gallic acid equation was used as a standard curve equation for the estimation of the total phenolic compound in the samples. In the standard curve equation $y=0.0052 x$, $R^{2}=0.9905, y$ denotes the absorbance and $x$ denotes the concentration of the compound. The values obtained for the concentration of total phenols are expressed as $\mathrm{mg}$ of $\mathrm{GA} / \mathrm{g}$ of extract in Figure 1.

The pairs of n-hexane stem extract and ethyl acetate stem extract were significantly different. Ethyl acetate stem extract was significantly different from that of ethanol stem extract, with $p<0.05$. All other pairs were not different.

\section{Flavonoid content}

The concentration of flavonoids was expressed in terms of quercetin equivalent ( $\mathrm{mg}$ of $\mathrm{QE} / \mathrm{g}$ of extract). The concentration of flavonoids in plant extracts from $P$. daemia ranged from $72.549 \pm 0.449 \mathrm{mg} / \mathrm{mL}$ to $400.196 \pm 0.339 \mathrm{mg} / \mathrm{mL}$ (Figure 2).

The leaf has a higher concentration than that of the stem. Ethanol extracts of the leaf have the highest concentration of the flavonoids and, generaly, ethanol extracts recorded significantly higher concentrations of flavonoids. The concentration of flavonoids in ethanol extracts of the leaf was $400.196 \mathrm{mg} \mathrm{QE} / \mathrm{g}$, followed by that of ethyl acetate with $388.627 \mathrm{mg} \mathrm{QE} / \mathrm{g}$ and the n-hexane extract with $338.725 \mathrm{mg}$ $\mathrm{QE} / \mathrm{g}$ at $10 \mathrm{mg} / \mathrm{mL}$. The lowest flavonoid concentration was recorded in the n-hexane extract of the stem. The quantities of the flavonoids extracted increases with the polarity of the extraction solvent. This result is in agreement with the observation of Min and Chun-Zhao (2005) when they compared extraction techniques in flavonoid extraction.

Our result revealed that the aerial part of the plant is highly loaded with flavonoids than the stem. Several studies

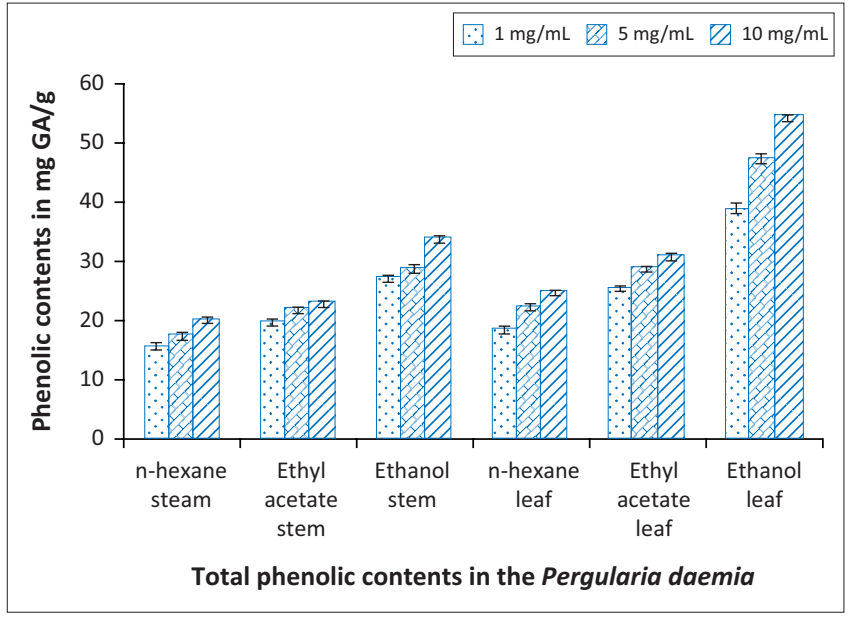

FIGURE 1: Estimated phenolic contents in the stem and leaf extracts of Pergularia daemia at $1 \mathrm{mg} / \mathrm{mL}, 5 \mathrm{mg} / \mathrm{mL}$ and $10 \mathrm{mg} / \mathrm{mL}$ of each extract.

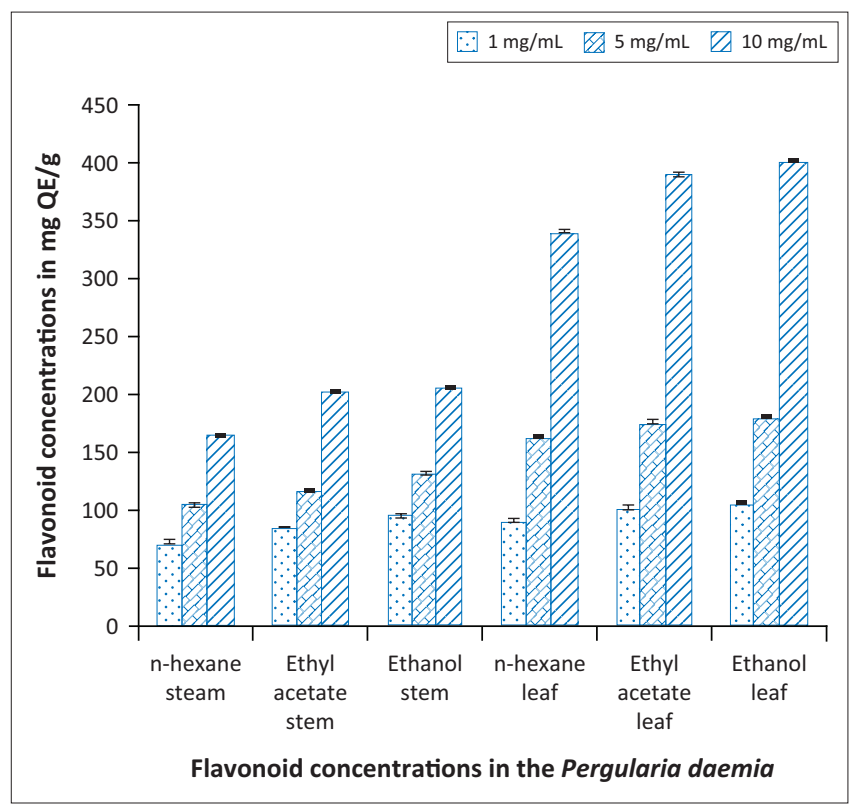

FIGURE 2: Estimated flavonoid concentrations in the stem and leaf of Pergularia daemia at $1 \mathrm{mg} / \mathrm{mL}, 5 \mathrm{mg} / \mathrm{mL}$ and $10 \mathrm{mg} / \mathrm{mL}$ of each extract.

reported that flavonoids present in herbs significantly contributed to their antioxidant properties and healing ability. Also, flavonoids are found to be effective scavengers of most oxidising molecules, including single oxygen and various free radicals (Manik et al. 2014).

The data obtained were subjected to statistical analysis. It was found that only the n-hexane leaf extract and ethyl acetate leaf extract were different significantly at $p<0.05$.

\section{Antioxidant activity}

\section{2,2-diphenyl-1-picrylhydrazyl radical scavenging activity}

The percentage inhibition of $P$. daemia over DPPH free radicals varied from $34.65 \%$ to $84.90 \%$. The activity was expressed as $\mathrm{IC}_{50}(\mu \mathrm{g} / \mathrm{mL})$, that is, the minimum concentration of the extract capable of scavenging $50 \%$ of the DPPH radicals. The $\mathrm{IC}_{50}$ value of ascorbic acid with the minimum concentration 
at $5.67 \mu \mathrm{g} / \mathrm{mL}$ was enough to scavenge the DPPH radical, which is considered to be chemotherapeutically significant $\left(\mathrm{IC}_{50}<10 \mu \mathrm{g} / \mathrm{mL}\right.$ ) with potency that could be used as a reference (Tian et al. 2013). The parallel examination of ascorbic acid as a reference with antioxidant activity of plant extracts is illustrated in Figure 3 and Figure 4.

Figure 3 shows the antioxidant activity of an ethanolic stem extract of $P$. daemia at $10.19 \mu \mathrm{g} / \mathrm{mL}$ in close range with ascorbic acid obtained at $5.67 \mu \mathrm{g} / \mathrm{mL}$ and $26.99 \mu \mathrm{g} / \mathrm{mL}$ for ethyl acetate stem extract, followed by $58.20 \mu \mathrm{g} / \mathrm{mL}$ for $\mathrm{n}$-hexane stem extract, which was observed to be very far from the standard.

Figure 4 shows $\mathrm{IC}_{50}$ activity of leaf extracts at $6.27 \mu \mathrm{g} / \mathrm{mL}$ (ethanol), $17.78 \mu \mathrm{g} / \mathrm{mL}$ (ethyl acetate) and $22.49 \mu \mathrm{g} / \mathrm{mL}$ (n-hexane). When compared with the standard at $5.67 \mu \mathrm{g} / \mathrm{mL}$,

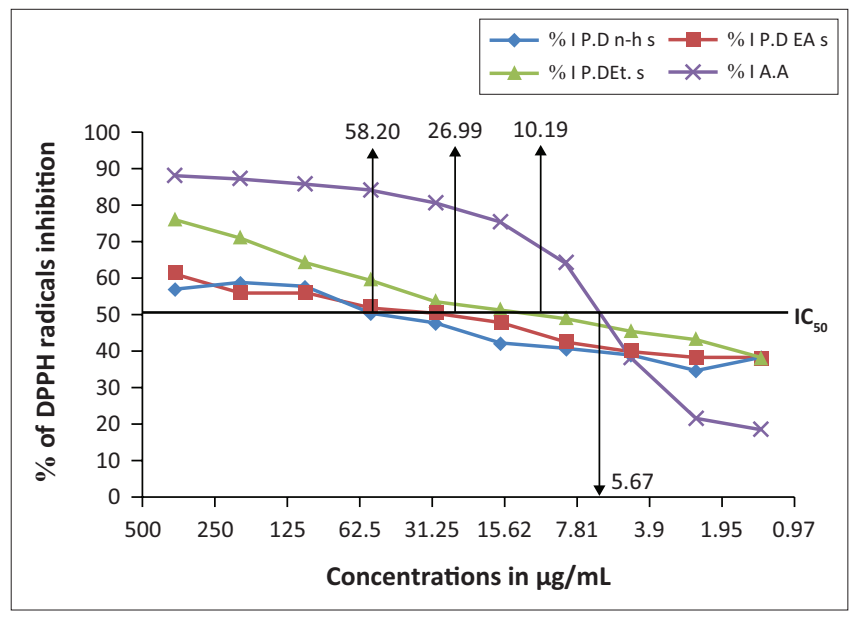

$\%$ I, percentage inhibition; P.D, Pergularia daemia; $\mathrm{n}$-h, $\mathrm{n}$-hexane; EA, ethyl acetate; Et, Ethanol; A.A, ascorbic acid; I, leaf; s, stem.

FIGURE 3: Percentage inhibition of DPPH (2,2-diphenyl-1-picrylhydrazyl) radical versus concentrations of stem extracts.

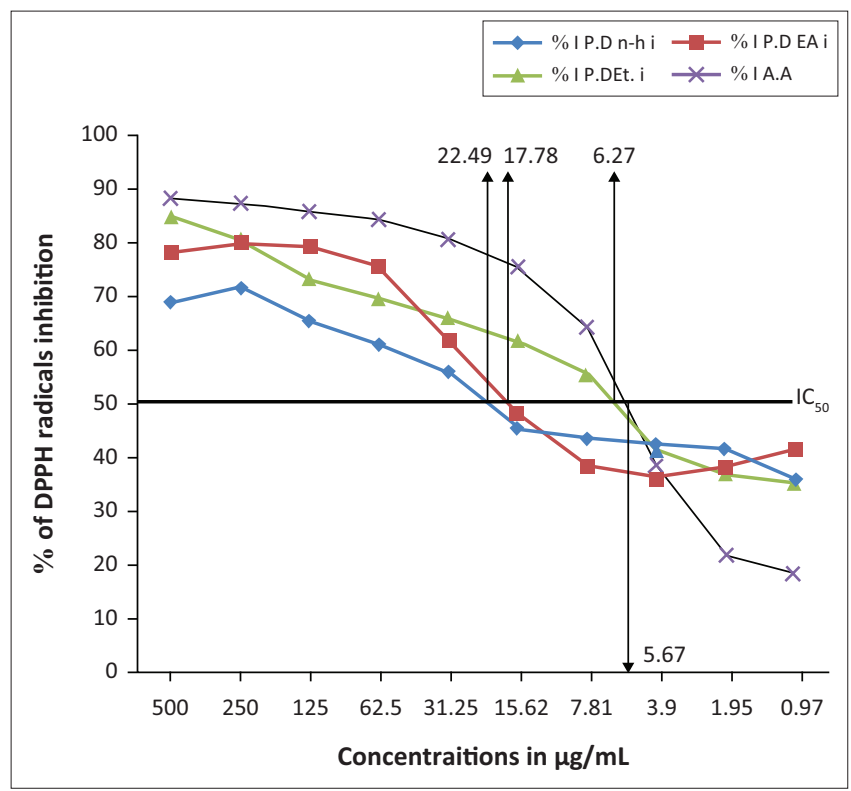

$\%$ I, percentage inhibition; P.D, Pergularia daemia; $\mathrm{n}$-h, $\mathrm{n}$-hexane; EA, ethyl acetate; Et, Ethanol; A.A, ascorbic acid; I, leaf; s, stem.

FIGURE 4: Percentage inhibition of DPPH (2,2-diphenyl-1-picrylhydrazyl) radical versus concentrations of leaf extracts. the ethanolic extract shows a very close antioxidant activity, followed by ethyl acetate, and the least antioxidant activity was observed in n-hexane. This study reveals that by consuming $P$. daemia, the free radicals that might be present in humans can be eliminated to get relief from oxidative stress and degenerative sicknesses. Ethanolic extract from $P$. daemia manifested the strongest capacity for scavenging $\mathrm{DPPH}$ radicals and was even effective at low concentration.

\section{Antimicrobial sensitivity}

The antibacterial sensitivity inhibition increases with the polarity of the solvent of extraction and with extract concentration. n-Hexane extract from the stem of $P$. daemia does not show sensitivity on the microorganisms at concentrations lower than $25 \mu \mathrm{g} / \mathrm{mL}$. Ethyl acetate stem extract shows sensitivity at $12.5 \mu \mathrm{g} / \mathrm{mL}$ and even at $6.25 \mu \mathrm{g} /$ $\mathrm{mL}$ on S. aureus, P. aeruginosa and K. pneumoniae (Table 2).

Meanwhile, full sensitivity was observed in ethanolic stem extract at all concentration levels. The ethyl acetate and ethanol extracts showed active inhibition on the growth of all tested microorganisms and the activities were comparable to that of gentamycin, the reference antibacterial drug, particularly at high concentration (Table 2 and Table 3). n-Hexane leaf extract shows sensitivity at $200 \mu \mathrm{g} / \mathrm{mL}, 100 \mu \mathrm{g} /$ $\mathrm{mL}, 50 \mu \mathrm{g} / \mathrm{mL}$ and $25 \mu \mathrm{g} / \mathrm{mL}$ on all organisms but is slightly sensitive at $12.56 \mu \mathrm{g} / \mathrm{mL}$ on S. aureus and B. subtilis (Table 3).

Four clinical strains of human pathogenic fungi were used in the study. Candida albicans, A. niger, R. stolon and $P$. notatum. Candida albicans and $A$. niger were the only fungi that were sensitive to the n-hexane stem extract inhibitory action at high concentration, although all the four fungi were sensitive to the leaf extract (Table 4 and Table 5). Rhizopus stolonifier and P. notatum were resistant to n-hexane leaf extract but were inhibited by other extracts, particularly at high concentration. Ethanol extracts for both leaf and stem were active in curbing the activities of the fungi, but they were not comparable to that of tioconazole, even at high concentration of extracts.

All fungi were resistant to the action of extracts at low concentrations, but ethanol extract of the leaf, showed inhibition at all levels. Also, inhibition activity increases with the polarity of extracts as well as concentration.

In the analysis of the zones of inhibition produced by the extracts, it was observed that ethanolic extracts of $P$. daemia showed prominent antimicrobial activity against all microorganisms. Thus, the ethanolic extracts were more potent compared to $n$-hexane and ethyl acetate extracts. From Table 1, the preliminary phytochemical studies reveal the presence of tannins, terpenoids, alkaloids and flavonoids in high concentration in ethanol extracts, which may contribute to the inhibition of microbial activities as observed. The antimicrobial inhibition results of $P$. daemia extract buttress the literature on the plant usage to combat bacterial 
TABLE 2: Antibacterial activities of extracts of Pergularia daemia (stem).

\begin{tabular}{|c|c|c|c|c|c|c|c|}
\hline \multirow[t]{2}{*}{ Extracts } & \multirow{2}{*}{$\begin{array}{l}\text { Extract concentration/ } \\
\text { reference/control }(\mathrm{mg} / \mathrm{mL})\end{array}$} & \multicolumn{6}{|c|}{ Diameter of zone of inhibition of bacteria $(\mathrm{mm})$} \\
\hline & & S. aureus & E. coli & B. subtilis & P. aeruginosa & K. pneumoniae & S. typhi. \\
\hline \multirow{7}{*}{$\begin{array}{l}\text { P. daemia } \\
\text { Stem } \\
\text { n-Hexane }\end{array}$} & 200 & $19 \pm 1.41$ & $17 \pm 1.41$ & $19 \pm 1.41$ & $15 \pm 1.41$ & $17 \pm 1.41$ & $15 \pm 1.41$ \\
\hline & 100 & $15 \pm 1.41$ & $14 \pm 0$ & $15 \pm 1.41$ & $13 \pm 1.41$ & $14 \pm 0$ & $12 \pm 0$ \\
\hline & 50 & $13 \pm 1.41$ & $12 \pm 0$ & $13 \pm 1.41$ & $10 \pm 0$ & $12 \pm 0$ & $10 \pm 0$ \\
\hline & 25 & $10 \pm 0$ & $10 \pm 0$ & $11 \pm 1.41$ & - & $10 \pm 0$ & - \\
\hline & 12.5 & - & - & - & - & - & - \\
\hline & n-Hexane & - & - & - & - & - & - \\
\hline & Gentamycin (mg/mL) & $39 \pm 1.41$ & $39 \pm 1.41$ & $38 \pm 0$ & $39 \pm 1.41$ & $38 \pm 0$ & $40 \pm 0$ \\
\hline \multirow{7}{*}{$\begin{array}{l}\text { P. daemia } \\
\text { Stem } \\
\text { Ethyl acetate }\end{array}$} & 200 & $27 \pm 1.41$ & $23 \pm 1.41$ & $23 \pm 1.41$ & $25 \pm 1.41$ & $23 \pm 1.41$ & $24 \pm 0$ \\
\hline & 100 & $23 \pm 1.41$ & $18 \pm 0$ & $18 \pm 0$ & $22 \pm 2.83$ & $20 \pm 0$ & $20 \pm 0$ \\
\hline & 50 & $19 \pm 1.41$ & $16 \pm 0$ & $14 \pm 0$ & $18 \pm 2.83$ & $18 \pm 0$ & $17 \pm 1.41$ \\
\hline & 25 & $16 \pm 2.83$ & $13 \pm 1.41$ & $12 \pm 0$ & $14 \pm 0$ & $14 \pm 0$ & $13 \pm 1.41$ \\
\hline & 12.5 & $13 \pm 1.41$ & $10 \pm 0$ & $10 \pm 0$ & $12 \pm 0$ & $12 \pm 0$ & $10 \pm 0$ \\
\hline & Ethyl acetate & - & - & - & - & - & - \\
\hline & Gentamycin (mg/mL) & $39 \pm 1.41$ & $39 \pm 1.41$ & $38 \pm 0$ & $39 \pm 1.41$ & $38 \pm 0$ & $40 \pm 0$ \\
\hline \multirow{8}{*}{$\begin{array}{l}\text { P. daemia } \\
\text { Stem } \\
\text { Ethanol }\end{array}$} & 200 & $31 \pm 1.41$ & $30 \pm 0$ & $30 \pm 0$ & $29 \pm 1.41$ & $30 \pm 0$ & $28 \pm 0$ \\
\hline & 100 & $28 \pm 0$ & $23 \pm 4.24$ & $27 \pm 1.41$ & $26 \pm 2.83$ & $27 \pm 1.41$ & $24 \pm 0$ \\
\hline & 50 & $24 \pm 0$ & $24 \pm 0$ & $24 \pm 0$ & $22 \pm 2.83$ & $24 \pm 0$ & $20 \pm 0$ \\
\hline & 25 & $20 \pm 0$ & $19 \pm 1.41$ & $20 \pm 0$ & $19 \pm 1.41$ & $19 \pm 1.41$ & $18 \pm 0$ \\
\hline & 12.5 & $16 \pm 2.83$ & $16 \pm 2.83$ & $16 \pm 2.83$ & $16 \pm 2.83$ & $15 \pm 1.41$ & $14 \pm 0$ \\
\hline & 6.25 & $13 \pm 1.41$ & $13 \pm 1.41$ & $12 \pm 2.83$ & $11 \pm 1.41$ & $12 \pm 0$ & $11 \pm 1.41$ \\
\hline & Ethanol & - & - & - & - & - & - \\
\hline & Gentamycin (mg/mL) & $40 \pm 0$ & $38 \pm 0$ & $39 \pm 1.41$ & $38 \pm 0$ & $39 \pm 1.41$ & $39 \pm 1.41$ \\
\hline
\end{tabular}

P. daemia, Pergularia daemia; S. aureus, Staphylococcus aureus; E. coli, Escherichia coli; B. subtilus, Bacillus subtilis; P. aeruginosa, Pseudomonas aeruginosa; K. pneumoniae, Klebsiella pneumoniae; S. typhi. Salmonella typhi.

TABLE 3: Antibacterial activities of extracts of Pergularia daemia (leaf).

\begin{tabular}{|c|c|c|c|c|c|c|c|}
\hline \multirow[t]{2}{*}{ Extracts } & \multirow{2}{*}{$\begin{array}{l}\text { Extract concentration/ } \\
\text { reference/control }(\mathrm{mg} / \mathrm{mL})\end{array}$} & \multicolumn{6}{|c|}{ Diameter of zone of inhibition of bacterial (mm) } \\
\hline & & S. aureus & E. coli & B. subtilis & P. aeruginosa & K. pneumoniae & S. typhi. \\
\hline \multirow{8}{*}{$\begin{array}{l}\text { P. daemia } \\
\text { Leaf } \\
\text { n-Hexane }\end{array}$} & 200 & $23 \pm 1.41$ & $17 \pm 1.41$ & $20 \pm 0$ & $17 \pm 1.41$ & $18 \pm 0$ & $17 \pm 1.41$ \\
\hline & 100 & $19 \pm 1.41$ & $14 \pm 0$ & $18 \pm 0$ & $14 \pm 0$ & $16 \pm 0$ & $14 \pm 0$ \\
\hline & 50 & $17 \pm 1.41$ & $12 \pm 0$ & $15 \pm 1.41$ & $12 \pm 0$ & $13 \pm 1.41$ & $12 \pm 0$ \\
\hline & 25 & $13 \pm 1.41$ & $10 \pm 0$ & $12 \pm 0$ & $10 \pm 0$ & $10 \pm 0$ & $10 \pm 0$ \\
\hline & 12.5 & $11 \pm 1.41$ & - & $10 \pm 0$ & - & - & - \\
\hline & 6.25 & - & - & - & - & - & - \\
\hline & $\mathrm{n}$-Hexane & - & - & - & - & - & - \\
\hline & Gentamycin (mg/mL) & $39 \pm 1.41$ & $39 \pm 1.41$ & $38 \pm 0$ & $39 \pm 1.41$ & $38 \pm 0$ & $40 \pm 0$ \\
\hline \multirow{8}{*}{$\begin{array}{l}\text { P. daemia Leaf } \\
\text { Ethyl acetate }\end{array}$} & 200 & $29 \pm 1.41$ & $25 \pm 1.41$ & $26 \pm 0$ & $27 \pm 1.41$ & $25 \pm 1.41$ & $26 \pm 0$ \\
\hline & 100 & $26 \pm 2.83$ & $20 \pm 0$ & $21 \pm 1.41$ & $24 \pm 0$ & $21 \pm 1.41$ & $21 \pm 1.41$ \\
\hline & 50 & $22 \pm 2.83$ & $16 \pm 0$ & $18 \pm 0$ & $20 \pm 0$ & $19 \pm 1.41$ & $18 \pm 0$ \\
\hline & 25 & $19 \pm 1.41$ & $14 \pm 0$ & $14 \pm 0$ & $17 \pm 1.41$ & $16 \pm 2.83$ & $14 \pm 0$ \\
\hline & 12.5 & $16 \pm 2.83$ & $12 \pm 0$ & $12 \pm 0$ & $13 \pm 1.41$ & $12 \pm 0$ & $12 \pm 0$ \\
\hline & 6.25 & $11 \pm 1.41$ & $10 \pm 0$ & $10 \pm 0$ & $10 \pm 0$ & $10 \pm 0$ & $10 \pm 0$ \\
\hline & Ethyl acetate & - & - & - & - & - & - \\
\hline & Gentamycin (mg/mL) & $39 \pm 1.41$ & $40 \pm 0$ & $38 \pm 0$ & $39 \pm 1.41$ & $38 \pm 0$ & $40 \pm 0$ \\
\hline \multirow{8}{*}{$\begin{array}{l}\text { P. daemia } \\
\text { Leaf } \\
\text { Ethanol }\end{array}$} & 200 & $30 \pm 0$ & $31 \pm 1.41$ & $30 \pm 0$ & $32 \pm 0$ & $32 \pm 0$ & $29 \pm 1.41$ \\
\hline & 100 & $28 \pm 0$ & $28 \pm 0$ & $28 \pm 0$ & $28 \pm 0$ & $28 \pm 0$ & $27 \pm 1.41$ \\
\hline & 50 & $25 \pm 1.41$ & $24 \pm 0$ & $25 \pm 1.41$ & $25 \pm 1.41$ & $25 \pm 1.41$ & $24 \pm 0$ \\
\hline & 25 & $22 \pm 2.83$ & $20 \pm 0$ & $21 \pm 1.41$ & $20 \pm 2.83$ & $22 \pm 2.83$ & $20 \pm 0$ \\
\hline & 12.5 & $18 \pm 0$ & $16 \pm 2.83$ & $17 \pm 1.41$ & $16 \pm 2.83$ & $18 \pm 0$ & $18 \pm 0$ \\
\hline & 6.25 & $14 \pm 0$ & $12 \pm 2.83$ & $13 \pm 1.41$ & $13 \pm 1.41$ & $14 \pm 0$ & $13 \pm 1.41$ \\
\hline & Ethanol & - & - & - & - & - & - \\
\hline & Gentamycin (mg/mL) & $40 \pm 0$ & $39 \pm 1.41$ & $39 \pm 1.41$ & $38 \pm 0$ & $39 \pm 1.41$ & $39 \pm 1.41$ \\
\hline
\end{tabular}

P. daemia, Pergularia daemia; S. aureus, Staphylococcus aureus; E. coli, Escherichia coli; B. subtilus, Bacillus subtilis; P. aeruginosa, Pseudomonas aeruginosa; K. pneumoniae Klebsiella pneumoniae; S. typhi. Salmonella typhi. 
TABLE 4: Antifungal activities of extracts of Pergularia daemia (stem).

\begin{tabular}{|c|c|c|c|c|c|}
\hline \multirow[t]{2}{*}{ Extracts } & \multirow{2}{*}{$\begin{array}{l}\text { Extract concentration/ } \\
\text { reference/control } \\
(\mathrm{mg} / \mathrm{mL})\end{array}$} & \multicolumn{4}{|c|}{$\begin{array}{c}\text { Diameter of zone of } \\
\text { inhibition of bacteria }(\mathrm{mm})\end{array}$} \\
\hline & & C. albicans & A. niger & R. stolon & P. notatum \\
\hline \multirow{8}{*}{$\begin{array}{l}\text { P. daemia } \\
\text { Stem } \\
\text { n-Hexane }\end{array}$} & 200 & $17 \pm 1.41$ & $15 \pm 1.41$ & - & - \\
\hline & 100 & $13 \pm 1.41$ & $12 \pm 0$ & - & - \\
\hline & 50 & $10 \pm 0$ & $10 \pm 0$ & - & - \\
\hline & 25 & - & - & - & - \\
\hline & 12.5 & - & - & - & - \\
\hline & 6.25 & - & - & - & - \\
\hline & $\mathrm{n}$-Hexane & - & - & - & - \\
\hline & Tioconazole $(0.7 \mathrm{mg} / \mathrm{mL})$ & $38 \pm 0$ & $27 \pm 1.41$ & $26 \pm 0$ & $27 \pm 1.41$ \\
\hline \multirow{8}{*}{$\begin{array}{l}\text { P. daemia } \\
\text { Stem } \\
\text { Ethyl } \\
\text { acetate }\end{array}$} & 200 & $17 \pm 1.41$ & $20 \pm 0$ & $17 \pm 1.41$ & $16 \pm 0$ \\
\hline & 100 & $14 \pm 0$ & $18 \pm 0$ & $14 \pm 0$ & $14 \pm 0$ \\
\hline & 50 & $12 \pm 0$ & $14 \pm 0$ & $12 \pm 0$ & $11 \pm 1.41$ \\
\hline & 25 & $10 \pm 0$ & $10 \pm 0$ & $10 \pm 0$ & - \\
\hline & 12.5 & - & - & - & - \\
\hline & 6.25 & - & - & - & - \\
\hline & Ethyl acetate & - & - & - & - \\
\hline & Tioconazole $(0.7 \mathrm{mg} / \mathrm{mL})$ & $38 \pm 0$ & $27 \pm 1.41$ & $26 \pm 0$ & $27 \pm 1.41$ \\
\hline \multirow{8}{*}{$\begin{array}{l}\text { P.D. } \\
\text { Stem } \\
\text { Ethanol }\end{array}$} & 200 & $20 \pm 0$ & $22 \pm 0$ & $20 \pm 0$ & $18 \pm 0$ \\
\hline & 100 & $18 \pm 0$ & $19 \pm 1.41$ & $18 \pm 0$ & $16 \pm 0$ \\
\hline & 50 & $16 \pm 0$ & $17 \pm 1.41$ & $16 \pm 0$ & $14 \pm 0$ \\
\hline & 25 & $14 \pm 0$ & $14 \pm 0$ & $14 \pm 0$ & $12 \pm 0$ \\
\hline & 12.5 & $12 \pm 0$ & $12 \pm 0$ & $12 \pm 0$ & $10 \pm 0$ \\
\hline & 6.25 & $10 \pm 0$ & $10 \pm 0$ & $10 \pm 0$ & - \\
\hline & Ethanol & - & - & - & - \\
\hline & Tioconazole $(0.7 \mathrm{mg} / \mathrm{mL})$ & $28 \pm 0$ & $28 \pm 0$ & $27 \pm 1.41$ & $28 \pm 0$ \\
\hline
\end{tabular}

P. daemia, Pergularia daemia; C. albicans, Candida albicans; A. niger, Aspergillus niger R. stolon, Rhizopus stolon; P. notatum, Penicillium notatum.

TABLE 5: Antifungal activities of extracts of Pergularia daemia (leaf).

\begin{tabular}{|c|c|c|c|c|c|}
\hline \multirow[t]{2}{*}{ Extracts } & \multirow{2}{*}{$\begin{array}{l}\text { Extract concentration/ } \\
\text { reference/control } \\
(\mathrm{mg} / \mathrm{mL})\end{array}$} & \multicolumn{4}{|c|}{$\begin{array}{c}\text { Diameter of zone of } \\
\text { inhibition of bacteria }(\mathrm{mm})\end{array}$} \\
\hline & & C. albicans & A. niger & R. stolon & P. notatum \\
\hline \multirow{8}{*}{$\begin{array}{l}\text { P. daemia } \\
\text { Leaf } \\
\text { n-Hexane }\end{array}$} & 200 & $14 \pm 0$ & $16 \pm 0$ & $14 \pm 0$ & $13 \pm 1.41$ \\
\hline & 100 & $12 \pm 0$ & $13 \pm 1.41$ & $12 \pm 0$ & $10 \pm 0$ \\
\hline & 50 & $10 \pm 0$ & $10 \pm 0$ & $10 \pm 0$ & - \\
\hline & 25 & - & - & - & - \\
\hline & 12.5 & - & - & - & - \\
\hline & 6.25 & - & - & - & - \\
\hline & n-Hexane & - & - & - & - \\
\hline & Tioconazole $(0.7 \mathrm{mg} / \mathrm{mL})$ & $28 \pm 0$ & $27 \pm 1.41$ & $26 \pm 0$ & $27 \pm 1.41$ \\
\hline \multirow{8}{*}{$\begin{array}{l}\text { P. daemia } \\
\text { Leaf } \\
\text { Ethyl } \\
\text { acetate }\end{array}$} & 200 & $20 \pm 0$ & $20 \pm 0$ & $18 \pm 0$ & $19 \pm 1.41$ \\
\hline & 100 & $18 \pm 0$ & $18 \pm 0$ & $14 \pm 0$ & $16 \pm 0$ \\
\hline & 50 & $14 \pm 0$ & $16 \pm 0$ & $12 \pm 0$ & $14 \pm 0$ \\
\hline & 25 & $12 \pm 0$ & $14 \pm 0$ & $10 \pm 0$ & $12 \pm 0$ \\
\hline & 12.5 & $10 \pm 0$ & $11 \pm 1.41$ & - & $10 \pm 0$ \\
\hline & 6.25 & - & - & - & - \\
\hline & Ethyl acetate & - & - & - & - \\
\hline & Tioconazole $(0.7 \mathrm{mg} / \mathrm{mL})$ & $28 \pm 0$ & $28 \pm 0$ & $26 \pm 0$ & $28 \pm 0$ \\
\hline \multirow{8}{*}{$\begin{array}{l}\text { P. daemia } \\
\text { Leaf } \\
\text { Ethanol }\end{array}$} & 200 & $23 \pm 1.41$ & $23 \pm 1.41$ & $21 \pm 1.41$ & $20 \pm 0$ \\
\hline & 100 & $20 \pm 0$ & $21 \pm 1.41$ & $18 \pm 0$ & $18 \pm 0$ \\
\hline & 50 & $18 \pm 0$ & $19 \pm 1.41$ & $16 \pm 0$ & $16 \pm 0$ \\
\hline & 25 & $15 \pm 1.41$ & $17 \pm 1.41$ & $14 \pm 0$ & $14 \pm 0$ \\
\hline & 12.5 & $13 \pm 1.41$ & $13 \pm 1.41$ & $12 \pm 0$ & $12 \pm 0$ \\
\hline & 6.25 & $11 \pm 1.41$ & $10 \pm 0$ & $10 \pm 0$ & $10 \pm 0$ \\
\hline & Ethanol & - & - & - & - \\
\hline & Tioconazole $(0.7 \mathrm{mg} / \mathrm{mL})$ & $28 \pm 0$ & $28 \pm 0$ & $27 \pm 1.41$ & $28 \pm 0$ \\
\hline
\end{tabular}

P. daemia, Pergularia daemia; C. albicans, Candida albicans; A. niger, Aspergillus niger R. stolon, Rhizopus stolon; P. notatum, Penicillium notatum. and fungal infections such as sexually transmitted diseases and skin diseases (Kokwaro 1981).

\section{Conclusion}

The results show that $P$. daemia has a high content of flavonoids and other phenolic compounds but can only be efficiently extracted with polar solvents. The high content of phenols and flavonoids in the plant extracts contributed to the strong antioxidant activity exhibited by the plant. Consequently, extracts of polar solvent showed more appreciable sensitivity against human pathogens as reported than the less polar extracts. In folk medicine, extraction is carried out with water or liquor (polar solvent), which is highly efficient in the extraction of the active ingredients from the studied plant. The results of this study present P. daemia as a potential plant for drug discovery. The plant is therefore recommended for further phytochemical analysis in order to isolate the active compounds responsible for the biological activities exhibited by the P. daemia.

\section{Competing interests}

The authors declare that they have no financial or personal relationship(s) that may have inappropriately influenced them in writing this article.

\section{Authors' contribution}

O. O. Dosumu designed the research, supervised the research work and did the write up. O. O. Dosumu was the project leader also. O. O. Ajetunmobi carried out the research and reported the results. O. A. Omole did the research experiments with Ajetunmobi and brought out the relevant references. P. A. Onocha did the proof reading and did the final corrections.

\section{Funding}

This research received no specific grant from any funding agency in the public, commercial, or not-for-profit sectors.

\section{Data availability statement}

Data sharing is not applicable to this article as no new data were created or analysed in this study.

\section{Disclaimer}

The views and opinions expressed in this article are those of the authors and do not necessarily reflect the official policy or position of any affiliated agency of the authors.

\section{References}

Bayer, A.W., Kirby, M.D.K., Sheris, J.C. \& Trick, M., 1986, 'Antibiotic susceptibility testing by standard single disc diffusion method', American Journal of Clinical Pathology 45, 493-496. https://doi.org/10.1093/ajcp/45.4_ts.493

Chang, S.T., Wu, J.H., Wang, S.H., Kang, P.L., Yang, N.S. \& Shyur, L.F., 2001, 'Antioxidant activity of extracts from Acacia confuse bark and heartwood', Journal of Agricultural and Food Chemistry 49, 3420-3424. https://doi.org/10.1021/ jf0100907 
Harborne, J.B., 1973, Phytochemical methods: A guide to modern techniques of plant analysis, Chapman and Hall Ltd., London, p. 279.

Karthishwaran, K. \& Mirunalini, S., 2010, 'Therapeutic potential of Pergularia daemia (Forsk)', International Journal of Pharmacy 6(6), 836-843. https://doi.org/ 10.3923/ijp.2010.836.843

Kelly, K., 2009, The history of medicine: Early civilizations prehistoric times to 500 A.D. pp. 29-50, Ferguson Publishing Company, New York.

Kokwaro, J.O., 1981, The role of medicinal plants in Primary Health care in East Africa, African natural Products Programme, London.

Kotnis, M.S., Patel, P., Menon, S.N. \& Sane, R.T., 2004, 'Rene protective effect of Hemidesmus indicus, an herbal drug used in Gentamicin-induced renal toxicity', Nephrology 3, 142-152. https://doi.org/10.1111/j.1440-1797.2004.00247.x

Kumarasamy, Y., Byres, M., Cox, P.J., Jasapars, M. \& Nahar, L., 2007, 'Screening seeds of some Scottish plants for free-radical scavenging activity', Phytotherapy Research 21, 615-621. https://doi.org/10.1002/ptr.2129

Li, F.K., Lai, C.K., Poon, W.T., Chan, A.Y.W., Chan, K.W., Tse, K.C. et al., 2004, 'Aggravation of non-steroidal anti-inflammatory drug-induced hepatitis and acute renal failure, by slimming drug containing anthraquinones', Nephrology Dialysis Transplantation 19(7), 1916-1917. https://doi.org/10.1093/ndt/gfh151

Manik, G., Barij, N.S., Julio, A.S., Pilar, M.V. \& Xesus, F., 2014, 'Flavonoids and phenolic compounds from Litsea polyantha Juss. Bark', International Electronic Conference on Synthetic Organic Chemistry 18, 1-5. http://www.sciforum.net/conference/ ecsoc-18.

Min, G. \& Chun-Zhao, L., 2005, 'Comparison of techniques for the extraction of flavonoids from cultured cells of Saussurea medusa maxim', World Journal of Microbiology Biotechnology 21, 1461-1463. https://doi.org/10.1007/s11274005-6809-1

Mohsen, M.S. \& Ammar, S.M.A., 2008, 'Total phenolic contents and antioxidan activity of corn tassel extracts', Food Chemistry 112, 595-598. https://doi.org/ 10.1016/j.foodchem.2008.06.014

Ncube, N.S., Afolayan, A.J. \& Okoh, A.I., 2008, 'Assessment techniques of antimicrobial properties of natural compounds of plant origin: Current methods and future trends', African Journal of Biotechnology 7(12), 1797-1806. https://doi.org/ $10.5897 /$ AJB07.613

Okwu, D.E., 2001, 'Evaluation of chemical composition of spices and flavouring agent' Global Journal of Pure and Applied Science 7, 445-459. https://doi.org/10.4314/ gjpas.v7i3.16293

Oloyede, G.K., Oke, M.J., Raji, Y. \& Olugbade, A.T., 2010, 'Antioxidant and anticonvulsant alkaloids in Crinum ornatum bulb extract', World Journal of Chemistry 5(1), 26-31.
Onocha, P.A. \& Ali, M.S., 2010, 'Antileishmaniasis, phytotoxicity and cytotoxicity of Nigerian Euphorbiaceae plants. 2: Phyllanthus amarus and Phyllanthus muellerianus extract', African Scientist 11(2), 85-90.

Osawa, T., 1994, Novel natural antioxidants for utilization in food and biological systems. Postharvest Biochemistry of plant food-materials in the tropics, pp. 241-251, Japan Scientific Press, Tokyo.

Quettier, D.C., Gressier, B., Vasseur, J. \& Dine, T., 2000, 'Phenolic compounds and antioxidant activities of buckwheat (Fagopyrum esculentum Moench) hulls and flour', Journal of Ethnopharmacology 72, 35-42. https://doi.org/10.1016/S03788741(00)00196-3

Rahila, T., Rukhsandra N., Zaidi A.A., Shamishilla, R., 1994, 'Phytochemical screening of medicinal plants belonging to Euphorbiaceae', Pakistan Veterinary Journal 14 160-162.

Shoge, M.O., Ndukwe, G.I. \& Amupitan, J., 2011, 'Phytochemical and antimicrobial studies on the aerial parts of Heliotropium indicum Linn', Annals of Biological Research 2(2), 129-136.

Singleton, V.L., Orthofer, R. \& Lamuela-Raventos, R.M., 1999, 'Analysis of total phenols and other oxidant substrates and antioxidants by means of Folin-Ciocalteu's reagent', Methods in Enzymology 299, 152-178. https://doi.org/10.1016/S00766879(99)99017-1

Sofowora, A.O., 1993, Medicinal plants and traditional medicine in Africa, 2nd edn., p. 320, University of Ife Press.

Sridevi, G., Prema, S. \& Sekar, S., 2014, 'Phytochemical analysis of P. daemia for its bioactive components through GCMS', IOSR Journal of Pharmacology 4, 41-46. https://doi.org/10.9790/3013-0405041046

Tanaka, M., Kuie, C.W., Nagashima, Y. \& Taguchi, T., 1998, 'Applications of antioxidative Maillard reaction products from histidine and glucose to sardine products', Nippon Suisan Gakaishi 54, 1409-1414. https://doi.org/10.2331/suisan.54.1409

Tian, H.P., Gin, K.L., Yun, H.T., Gwendoline, C.L. \& Marwardi, R., 2013, 'A new cytotoxic carbazole alkaloid isolated from stem bark of Malaysian Clausena excavata' Canadian Chemical Transactions 1, 168-170. https://doi.org/10.13179/ canchemtrans.2013.01.03.0027

World Health Organization, 2002, Traditional medicine strategy, WHO/EDM/ TRM/2002.1, a publication of World Health Organization, Geneva, Switzerland.

Yen, G.C., Duh, P.D. \& Chuang, D.Y., 2000, 'Antioxidant activity of anthraquinones and anthrone', Food Chemistry 70(4), 437-441. https://doi.org/10.1016/S0308-8146 (00)00108-4

Zhou, K. \& Yu, L., 2004, 'Effects of extraction solvent on wheat bran antioxidant activity estimation', Lebensmittel-Wissenschaft \& Technologie 37, 717-721. https://doi. org/10.1016/j.lwt.2004.02.008 